\title{
Torque ripples improvement of direct torque controlled five-phase induction motor drive using backstepping control
}

\author{
Hamdi Echeikh $^{1}$, Ramzi Trabelsi ${ }^{2}$, Hichem Kesraoui $^{3}$, Atif Iqbal ${ }^{4}$, Mohamed Faouzi Mimouni $^{5}$ \\ ${ }^{1,5}$ National Engineering School,University Monastir, Tunisia \\ ${ }^{2}$ High institute of Sciences and Technologies, University Sousse, Tunisia \\ ${ }^{3}$ High Institute of Technological Studies, Mahdia, Tunisia \\ ${ }^{4}$ University of Doha, Qatar
}

\begin{tabular}{l}
\hline \hline Article Info \\
\hline Article history: \\
Received Aug 10, 2019 \\
Revised Oct 9, 2019 \\
Accepted Oct 14, 2019 \\
\hline
\end{tabular}

Keywords:

Direct-backstepping control

Direct torque control

Multiphase motor

Rotor flux oriented control

Voltage source inverter

\begin{abstract}
The paper proposes Direct Torque Control (DTC) of a five-phase induction motor drive with reduced torque ripple. The method presented here is the DTC-Backstepping based on the classic DTC working with a constant switching frequency of the inverter. Another remarkable aspect is the complexity of the method proposed, both in the control unit of the inverter and in the number of correctors necessary for the control of the torque. The selection table and hysteresis have been eliminated. This method significantly improves the torque and flux oscillations and improves the dynamics of the drive by making it less sensitive to load torque disturbances. The proposed method is developed and designed using Matlab/SIMULINK to show the effectiveness and performances of the DTC-Backstepping.
\end{abstract}

This is an open access article under the CC BY-SA license.

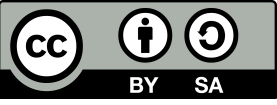

\section{Corresponding Author:}

Hamdi Echeikh,

National Engineering School of Monastir, Tunisia,

Rue Ibn Jazar 5000, Monastir Tunisia.

Tel: +31624644976

Email: echeikh_hamdi@hotmail.com

\section{INTRODUCTION}

Multiphase machines offer an interesting alternative to the reduction of the stresses applied to the switches as to the windings. Indeed, the multiplication of the number of phases allows a fractionation of the power and hence a reduction of the voltages switched to a given current. Moreover, these machines reduce the amplitude and increase the frequency of the torque ripples, thus enabling the mechanical load to filter them more easily. Finally, the multiplication of the number of phases offers increased reliability by allowing operation when one or more phases are open. Multiphase machines are present in the fields of marine, railway traction, petrochemical industry, avionics, automobile, etc. The rotor flux oriented control mostly employed in multiphase motor drives is based on effective control of the magnetic state. However, this structure generally requires the installation of a speed/position sensor on the shaft. Moreover, it remains very sensitive to the variations of the parameters of the machine, many research have developed this strategy of control applied for multiphase machines [1-6]. Direct torque control (DTC) has been initially developed for induction machines in the years 1986 and 1988 by TAKAHASHI and DEPENBROCK. In the literature there is an extensive research on DTC applied for multiphase machines [7-14]. In [7,12] a DTC strategy for dual three-phase induction motor drives is discussed. In [8] describes an investigation of direct torque control for multi-phase permanent magnet synchronous motor drives. A DTC for five-phase synchronous motor has 
been developed in [9]. Also in [11], authors established a DTC algorithms for a split-phase induction motor. Compared to vector control, the DTC control is much less sensitive to parametric variations and allows to obtain dynamics faster control. A good accuracy in measuring the position of the rotor is not necessary since only the sector in which the flux is located matters to determine the configuration to be used.On the other hand, the flux and torque of the machine must be estimated or observed using different ways. The synthesis of such estimators is not trivial and constitutes a difficulty for the implementation of this control [15]. By nature, torque oscillations exist in DTC drive. The reduction of the hysteresis bands with a given sampling period does not always have an effect on the amplitude of the torque oscillations. In this case, in order to reduce torque oscillations, it is necessary to decrease the sampling period. The switching frequency is not controlled, it varies according to the operating point. DTC with constant switching frequency using SVPWM is reported in [16,17], however, the algorithm is more complex, nevertheless, torque and flux oscillations are reduced. One find in [18], the extended DTC, this control uses selection table of optimal vectors and considers an additional input: the sign of the change of electromagnetic torque. In the extended DTC, the torque regulator has a threelevel output, unlike the conventional DTC where only two levels were considered. One can observe a reduction in torque oscillations. In $[19,20]$, the authors present an algorithm allowing to have a constant switching frequency, its main feature is the removal of the hysteresis regulators and the vector selection table, which eliminates the problems associated with them. With this control method, the inverter operates at a constant frequency, since a PWM technique is applied. The objective of this method is to realize a direct control of the stator flux vector in a reference frame linked to the stator, the polar components of these two vectors are obtained by their projections on the reference frame. From these components, the desired stator flux vector at a given instant is calculated. The PWM is applied to this vector to obtain the switching states of the inverter. Applications using fuzzy systems have been developed in [21,22], where the hysteresis blocks have been replaced by fuzzy controllers.vFuzzy logic is used to achieve a compromise between torque control and flux control, and they do not require an exact mathematical model of the machine. However, it draws strong current pulses which normally translates into higher torque ripple. The sliding mode control (SMC), due to its robustness to uncertainties and external perturbations, can be applied to uncertain and disturbed nonlinear systems. It is a question of defining a so-called sliding surface according to the states of the system. The synthesized global command consists of two terms: the first allows to approach this surface, the second allows the retention and the sliding along it [22]. The combination of SMC and DTC control reduces torque and flux ripples. Its main feature is the removal of the hysteresis regulators and the switching table, which eliminates the problems associated with them. The disadvantage of this association (DTC-SMG)is the use of the saturation function that introduces a static error that persists as well as the need to have a knowledge of the dynamics of the system. In [23], authors addresse a new approach to adapt the concept of the Predictive Control Model(MPC) to Direct Torque Control (DTC) in the five-phase induction motor control. The proposed algorithm improves the performance of a DTC controller by retaining the electromagnetic torque and the stator flux modulus within predefined hysteresis bands while minimizing switching losses. The MPC controller extracts the strings of switching sequences on the forecast horizon. Dynamic programming is implemented to select the switching sequences that minimize the cost function on power losses. Both simulations and experimental are carried out on specific models and the results verify the advantages of the proposed DTC method in comparison with conventional DTC. Model-based predictive direct control methods are advanced control strategies in the field of power electronics to control induction machines [24]. The torque control prediction (PTC) method evaluates the electromagnetic torque and the stator flux in the cost function. The switching vector selected for use in insulated gate bipolar transistors (IGBT) which minimizes error between references and predicted values. System constraints can be easily understood.Behavior and robustness and transient performance are evaluated. Due to the inconvenient of the DTC control such as high torque and currents ripples push us to think and to design new control to improve the direct torque control technique. The idea in this paper is to use the combination between the DTC control and a non-linear control in this paper is the Backstepping control. As the authors know there is no study in the literature treated this approach applied to the multiphase motor and specially five-phase induction motor.

\section{DTC-BACKSTEPPING CONTROL OF FIVE-PHASE INDUCTION MOTOR}

The induction motor drive system used to develop the proposed controller strategy is composed mainly of five-phase voltage source inverter and a symmetrical five-phase induction motor with phase shift of the windings equal to $2 \pi / 5$. All the components of the drive system are schematically illustrated in the Figure 1 . 
Using various assumptions, such as negligible core losses, uniform air gap, sinusoidal MMF distribution and symmetrical distributed windings, then the five-phase induction motor model using the vector space decomposition method presented in [25]. The model represented in two orthogonal planes, where the first plane is involved in the fundamental torque production $(\alpha-\beta$ representing the fundamental component and contains the harmonics of order $10 n \pm 1, n=0,1,2,3 \ldots)$. The second plane is connected to the losses in the motor $(x-y$ represented the supply harmonics of the order $10 n \pm 3, n=0,1,2,3 \ldots)$. Finally, the zero-sequence component is not considered due to the neutral point isolation isolation $(z$-axis representing the supply harmonics of order $5 n, n=0,1,2,3 \ldots)$. Using the selection of the stator currents in two planes $\alpha-\beta$ and $x-y$ and the rotor fluxes in the plane $\alpha-\beta$ as state variables, $x_{1}=i_{s \alpha}, x_{2}=i_{s \beta}, x_{3}=\psi_{r \alpha}, x_{4}=\psi_{r \beta}, x_{5}=i_{s x}$ and $x_{6}=i_{s y}$. The motor drive equations can be expressed in the following form

$$
\left\{\begin{array}{l}
\dot{x_{1}}=c_{1} x_{3}+c_{2} \omega x_{4}-c_{3} x_{1}+c_{4} v_{1} \\
\dot{x_{2}}=c_{1} x_{4}-c_{2} \omega x_{3}-c_{3} x_{2}+c_{4} v_{2} \\
\dot{x_{3}}=-c_{5} x_{3}-\omega x_{4}+c_{6} x_{1} \\
\dot{x_{4}}=-c_{5} x_{4}+\omega x_{3}+c_{6} x_{2} \\
\dot{x_{5}}=-c_{7} x_{5}+c_{8} v_{3} \\
\dot{x_{6}}=-c_{7} x_{6}+c_{8} v_{4} \\
\dot{\omega}=m_{1}\left(x_{3} x_{2}-x_{4} x_{1}\right)-m_{2} T_{l}-m_{3} \omega
\end{array}\right.
$$

With the coefficients given by

$c_{1}=\frac{(1-\sigma)}{\sigma M \tau_{r}}, c_{2}=\frac{(1-\sigma)}{\sigma M}, c_{3}=\left(\frac{1}{\sigma \tau_{s}}+\frac{(1-\sigma)}{\sigma \tau_{r}}\right), c_{4}=\frac{1}{\sigma L_{s}}, c_{5}=\frac{1}{\tau r}, c_{6}=\frac{M}{\tau r}, c_{7}=\frac{R_{s}}{L_{l s}}, c_{8}=\frac{1}{L_{l s}}$ $\sigma=1-\frac{M^{2}}{L_{s} L_{r}}, \tau_{s}=\frac{L_{s}}{R_{s}}, \tau_{r}=\frac{L_{r}}{R_{r}}, m_{1}=\frac{P^{2} M}{J_{m} L_{r}}, m_{2}=\frac{P}{J_{m}}, m_{3}=\frac{B_{m}}{J_{m}}$

The inputs signals of system above are the applied stator voltages $v_{1}=v_{s \alpha}, v_{2}=v_{s \beta}, v_{3}=v_{s x}$ and $v_{1}=v_{s y}$. The equations represent the electrical speed $\omega$ and all the motor parameters, $M$ is the mutual inductance, $R_{s}$ is the stator resistance, $R_{r}$ the rotor resistance, $L_{r}$ is the rotor inductance, $L_{s}$ is the stator inductance and $L_{l s}$ is the stator leakage inductance. One presented a novel state variables to describe the novel model to developed the DTC-Backstepping controller, however, the separation of the model of fivephase induction motor is released into two different parts, mechanical part and electrical part, the new state variables are given as follows

$$
\left\{\begin{array}{l}
T_{v}=\psi_{r \alpha} i_{s \beta}-\psi_{r \beta} i_{s \alpha}=x_{3} x_{2}-x_{4} x_{1} \\
\psi_{v}=\frac{1}{2}\left(x_{3}^{2}+x_{4}^{2}\right) \\
X_{v}=x_{3} x_{1}+x_{4} x_{2}
\end{array}\right.
$$

Where $T_{v}$ is a virtual torque, the relation between the electromagnetic torque and the virtual torque is $T_{e m}=m_{1} T_{v} . \psi_{v}$ is virtual flux, the relation between the rotor flux and the virtual flux is $\psi_{v}=\psi_{r}^{2}$, where $\psi_{r}^{2}=\psi_{r \alpha}^{2}+\psi_{r \beta}^{2}$. In practice the components $\psi_{r \alpha}$ and $\psi_{r \beta}$ are derived from the five-phase induction motor voltage model or current model given by

$$
\left\{\begin{array}{l}
\psi_{s \alpha}=\int\left(v_{s \alpha}-R_{s} i_{s \alpha}\right) d t \\
\psi_{s \beta}=\int\left(v_{s \beta}-R_{s} i_{s \beta}\right) d t
\end{array}\right.
$$

The rotor flux can be derived as following

$$
\left\{\begin{array}{l}
\psi_{r \alpha}=L_{r}\left(\psi_{s \alpha}-\sigma L_{s} i_{s \alpha}\right) \\
\psi_{r \beta}=L_{r}\left(\psi_{s \beta}-\sigma L_{s} i_{s \beta}\right)
\end{array}\right.
$$

The five-phase induction motor model can be separated into electrical and mechanical parts using the new state variables given above, the mechanical part is

$$
\dot{\omega}=m_{1} T_{v}-m_{2} T_{l}-m_{3} \omega
$$


The derivative of the virtual torque is given by

$$
\dot{T_{v}}=\dot{x_{3}} x_{2}+x_{3} \dot{x_{2}}-\dot{x_{4}} x_{1}-x_{4} \dot{x_{1}}
$$

Replacing the derivative $x_{1}, x_{2}, x_{3}$ and $x_{4}$ from equation (1) one obtain:

$$
\dot{T}_{v}=-\left(c_{3}+c_{5}\right)\left(x_{3} x_{2}-x_{4} x_{1}\right)-\omega\left(x_{3} x_{1}+x_{4} x_{2}\right)-c_{2} \omega\left(x_{3}^{2}+x_{4}^{2}\right)+c_{4}\left(x_{3} v_{2}-x_{4} v_{1}\right)
$$

Using equation (2), the equation (7) can be rewritten as

$$
\dot{T}_{v}=-\left(c_{3}+c_{5}\right) T_{v}-\omega X_{v}-2 c_{2} \omega \psi_{v}+c_{4} u_{T}
$$

Where $u_{T}=x_{3} v_{2}-x_{4} v_{1}=\psi_{r \alpha} v_{s \beta}-\psi_{r \beta} v_{s \alpha}$ The derivative of the virtual rotor flux $\psi_{v}$ gives:

$$
\dot{\psi_{v}}=\dot{x_{3}} x_{3}+\dot{x_{4}} x_{4}
$$

Using equation (1), equation (9) can be rewritten as

$$
\dot{\psi}_{v}=-c_{5}\left(x_{3}^{2}+x_{4}^{2}\right)+c_{6}\left(x_{3} x_{1}+x_{4} x_{2}\right)
$$

Using equation (2), equation (10) becomes

$$
\dot{\psi}_{v}=-c_{5} X_{v}+c_{6} \psi_{v}
$$

The derivative of $X_{v}$ gives as follows

$$
\dot{X_{v}}=\dot{x_{3}} x_{1}+x_{1} \dot{x_{3}}+\dot{x_{4}} x_{2}+x_{4} \dot{x_{2}}
$$

Using the equation (1), equation (12) becomes:

$$
\dot{X}_{v}=-\left(c_{3}+c_{5}\right)\left(x_{3} x_{1}+x_{4} x_{2}\right)+\omega\left(x_{3} x_{2}-x_{4} x_{1}\right)+c_{6}\left(x_{1}^{2}+x_{2}^{2}\right)+c_{1}\left(x_{3}^{2}+x_{4}^{2}\right)+c_{4}\left(x_{3} v_{1}+x_{4} v_{2}\right)
$$

Replacing the expressions of equation (2) in equation (13), one obtains:

$$
\dot{X}_{v}=-\left(c_{3}+c_{5}\right) X_{v}+\omega T_{v}+c_{6}\left(x_{1}^{2}+x_{2}^{2}\right)+2 c_{1} \psi_{v}+c_{4} u_{\psi}
$$

Where $u_{\psi}=x_{3} v_{1}+x_{4} v_{2}=\psi_{r \alpha} v_{1}+\psi_{r \beta} v_{2}$ Indeed, for the mechanical part, the virtual torque $T_{v}$ is controlled with a virtual torque voltage $u_{T}$ and for the electrical part, the virtual rotor flux $\psi_{v}$ is controlled by the virtual rotor flux voltage $u_{\psi}$. This will simplify the design of the DTC-backstepping controller in the following section based on the mechanical and electrical parts. One design by $\omega^{*}$ the electrical motor speed reference, the speed error is given by:

$$
z_{1}=\omega^{*}-\omega
$$

The derivative of speed error can be rewritten as

$$
\dot{z}_{1}=\dot{\omega}^{*}-\dot{\omega}=\dot{\omega}^{*}-m_{1} T_{v}+m_{2} T_{l}+m_{3} \omega
$$

Choosing the derivative of the error $\dot{z}_{1}=-k_{1} z_{1}$ where $k_{1}$ is a positive constant. One can get the reference of the virtual torque $T_{v}$ as

$$
T_{v}^{*}=\left(\dot{\omega}^{*}+m_{2} T_{l}+m_{3} \omega+k_{1} z_{1}\right) / m_{1}
$$

The error of the virtual torque gives by $z_{2}=T_{v}^{*}-T_{v}$, the derivative of $z_{2}$ gives in equation (18).

$$
\dot{z}_{2}=\dot{T}_{v}^{*}-\dot{T}_{v}=\dot{T}_{v}^{*}+\left(c_{3}+c_{5}\right) T_{v}+\omega X_{v}+2 c_{2} \omega \psi_{v}-c_{4} u_{T}
$$

Choosing the derivative of the error $\dot{z}_{2}=-k_{2} z_{2}$, one can get the virtual torque voltage $u_{T}$ as

$$
u_{T}=\left(\dot{T_{v}^{*}}+\left(c_{3}+c_{5}\right) T_{v}+\omega X_{v}+2 c_{2} \omega \psi_{v}+k_{2} z_{2}\right) / c_{4}
$$

Using equation (17) the equation (19) can be rewritten as

$$
u_{T}=\left(\left(\ddot{\omega} *+m_{2} \dot{T}_{l}+m_{3} \dot{\omega}-k_{1}^{2} z_{1}\right) / m_{1}+\left(c_{3}+c_{5}\right) T_{v}+\omega X_{v}+2 c_{2} \omega \psi_{v}+k_{2} z_{2}\right) / c_{4}
$$


Finally, replacing the expression of $\dot{\omega}$ from equation (1), the expression of the virtual voltage $u_{T}$ given as follows

$$
u_{T}=\left(\left(\ddot{\omega} *+m_{2} \dot{T}_{l}-m_{3} m_{2} T_{l}-m_{3}^{2} \omega-k_{1}^{2} z_{1}+m_{1}\left(m_{3}+c_{3}+c_{5}\right) T_{v}\right) / m_{1}+\omega X_{v}+2 c_{2} \omega \psi_{v}+k_{2} z_{2}\right) / c_{4}
$$

One assume that the virtual rotor flux of the five-phase induction motor given by $\psi_{v}^{*}$, then its error is given by:

$$
z_{3}=\psi_{v}^{*}-\psi_{v}
$$

The dynamic of the error of the virtual rotor flux is given by the following equation:

$$
\dot{z}_{3}=\dot{\psi}_{v}^{*}-\dot{\psi}_{v}=\dot{\psi}_{v}^{*}+2 c_{5} \psi_{v}-c_{6} X_{v}
$$

Choosing the dynamic of the error $\dot{z_{3}}=-k_{3} z_{3}$, one obtains the virtual control $X_{v}^{*}$ as:

$$
X_{v}^{*}=\left(\dot{\psi_{v}^{*}}+2 c_{5} \psi_{v}+k_{3} z_{3}\right) / c_{6}
$$

Let is now define the error of the virtual control $X_{v}$ as:

$$
z_{4}=X_{v}^{*}-X_{v}
$$

Its dynamic error is given by:

$$
\dot{z}_{4}=\dot{X}_{v}^{*}-\dot{X}_{v}
$$

Using equation (14), equation (26) becomes

$$
\dot{z}_{4}=\dot{X}_{v}^{*}+\left(c_{3}+c_{5}\right) X_{v}-\omega T_{v}-c_{6}\left(x_{1}^{2}+x_{2}^{2}\right)-2 c_{1} \psi_{v}-c_{4} u_{\psi}
$$

Choosing the dynamic of the error $\dot{z}_{4}=-k_{4} z_{4}$, where $k_{4}$ is a positive constant, then the virtual rotor flux $u_{\psi}$ obtains as

$$
u_{\psi}=\left(\dot{X}_{v}^{*}+\left(c_{3}+c_{5}\right) X_{v}-\omega T_{v}-c_{6}\left(x_{1}^{2}+x_{2}^{2}\right)-2 c_{1} \psi_{v}+k_{4} z_{4}\right) / c_{4}
$$

Using equation (24), one can rewrite the equation (28) as

$$
u_{\psi}=\left(\left(\ddot{\psi}_{v}^{*}+2 c_{5} \dot{\psi}_{v}-k_{3}^{2} z_{3}\right) / c_{6}+\left(c_{3}+c_{5}\right) X_{v}-\omega T_{v}-c_{6}\left(x_{1}^{2}+x_{2}^{2}\right)-2 c_{1} \psi_{v}+k_{4} z_{4}\right) / c_{4}
$$

Replacing the expression of $\dot{\psi_{v}}$ gives by equation (11) in equation (29), one obtains

$$
u_{\psi}=\left(\left(\ddot{\psi}_{v}^{*}+2 c_{5}\left(-2 c_{5} \psi_{v}+c_{6} X_{v}\right)-k_{3}^{2} z_{3}\right) / c_{6}+\left(c_{3}+c_{5}\right) X_{v}-\omega T_{v}-c_{6}\left(x_{1}^{2}+x_{2}^{2}\right)-2 c_{1} \psi_{v}+k_{4} z_{4}\right) / c_{4}
$$

From the two virtual voltages, both for torque and flux, one can acquire the stator voltages in the $(\alpha-\beta)$ frame.

$$
\left\{\begin{array}{l}
v_{1}=v_{s \alpha}=\left(x_{3} u_{\psi}-x_{3} u_{T}\right) / 2 \psi_{v} \\
v_{2}=v_{s \beta}=\left(x_{4} u_{\psi}+x_{3} u_{T}\right) / 2 \psi_{v}
\end{array}\right.
$$

Now, One need to determinate the control voltages $v_{3}$ and $v_{4}$, then one define the following current errors $z_{5}$ and $z_{6}$

$$
\left\{\begin{array}{l}
z_{5}=i_{s x}^{*}-i_{s x}=i_{s x}^{*}-x_{5} \\
z_{6}=i_{s y}^{*}-i_{s y}=i_{s y}^{*}-x_{6}
\end{array}\right.
$$

The dynamic of the currents errors $z_{5}$ and $z_{6}$ given as follow

$$
\left\{\begin{array}{l}
\dot{z_{5}}=i_{s x}^{\dot{*}}-\dot{i_{s x}}=i_{s x}^{\dot{*}}-\dot{x_{5}} \\
\dot{z_{6}}=\dot{i}_{s y}^{*}-\dot{i_{s y}}=\dot{i}_{s y}^{*}-\dot{x_{6}}
\end{array}\right.
$$

Choosing the derivative of the errors $\dot{z_{5}}=-k_{5} z_{5}$ and $\dot{z}_{6}=-k_{6} z_{6}$, the stator voltages in the reference $(x-y)$ obtained in the following equation

$$
\left\{\begin{array}{l}
v_{3}=v_{s x}=\left(i_{s x}^{*}-c_{7} x_{5}+k_{5} z_{5}\right) / c_{8} \\
v_{4}=v_{s y}=\left(i_{s y}^{*}-c_{7} x_{6}+k_{6} z_{6}\right) / c_{8}
\end{array}\right.
$$




\section{STABILITY ANALYSIS}

Usually it is difficult to find the asymptotic stability of time-varying systems because it is very difficult to find Lyapunov functions with a negative definite derivative. We know in case of autonomous (time invariant) systems, if $\mathrm{V}$ is negative semi-definite, then it is possible to know the asymptotic behaviors by invoking invariant-set theorems. However, the flexibility is not available for time-varying systems. This is where Babarlat's lemma comes into picture.

\subsection{Lemma: Barbalt's Lemma}

Suppose $f(t) \in C^{1}(a, \infty)$ and $\lim _{t \rightarrow \infty} f(t)=\gamma$ where $\gamma<\infty$. If $f^{\prime}$ is uniformly continuous, then $\lim _{t \rightarrow \infty} f^{\prime}(t)=0$.

\subsection{Proof}

One will prove the result by contradiction. $\lim _{t \rightarrow \infty} f(t) \neq 0$. Then $\ni \epsilon>0$ and a monotone increasing sequence $\left\{t_{n}\right\}$ such that $t_{n} \rightarrow \infty$ as $n \rightarrow \infty$ and $\left|f^{\prime}(t)\right| \geq \epsilon$ for all $n \in N$. Since $f^{\prime}(t)$ is uniformly continuous, for such $\epsilon, \ni \chi>0$ such that $\forall n \in N$.

$$
\left|t-t_{n}\right|<\chi \Rightarrow\left|f^{\prime}(t)-f^{\prime}\left(t_{n}\right)\right| \leq \varepsilon / 2
$$

Hence if $t \in\left[t_{n}, t_{n}+\chi\right]$ then

$$
\left|f^{\prime}(t)\right|=\left|f^{\prime}\left(t_{n}\right)-\left(f^{\prime}\left(t_{n}\right)-f^{\prime}(t)\right)\right| \geq\left|f^{\prime}(t)\right|-\left|f^{\prime}\left(t_{n}\right)-f^{\prime}(t)\right| \geq \epsilon-\epsilon / 2=\epsilon / 2
$$

Then since $f(t) \in C^{1}$ one have

$$
\left|\int_{a}^{t_{n}+\chi} f^{\prime}(t) d t-\int_{a}^{t_{n}} f^{\prime}(t) d t\right|=\left|\int_{t_{n}}^{t_{n}+\chi} f^{\prime}(t) d t\right| \geq \int_{t_{n}}^{t_{n}+\chi}\left|f^{\prime}(t)\right| d t \geq \int_{t_{n}}^{t_{n}+\chi} \epsilon / 2 d t=\chi \epsilon / 2
$$

However

$$
\begin{gathered}
\lim _{t \rightarrow \infty}\left|\int_{a}^{t_{n}+\chi} f^{\prime}(t) d t-\int_{a}^{t_{n}} f^{\prime}(t) d t\right|=\lim _{t \rightarrow \infty}\left|f\left(t_{n}+\chi\right)-f\left(t_{n}\right)\right| \\
=\left|\lim _{t \rightarrow \infty} f\left(t_{n}+\chi\right)-\lim _{t \rightarrow \infty} f\left(t_{n}\right)\right|=|\gamma|-|\gamma|=0
\end{gathered}
$$

This is a contradiction. Therefore $\lim _{t \rightarrow \infty} f^{\prime}(t)=0$

\subsection{Application of the Lemma}

One assume the Lyapunov function is

$$
V=\frac{z_{1}^{2}+z_{2}^{2}+z_{3}^{2}+z_{4}^{2}+z_{5}^{2}+z_{6}^{2}}{2}
$$

The derivative of the Lyapunov function given by

$$
\dot{V}=z_{1} \dot{z}_{1}+z_{2} \dot{z}_{2}+z_{3} \dot{z}_{3}+z_{4} \dot{z}_{4}+z_{5} \dot{z}_{5}+z_{6} \dot{z}_{6}=-k_{1} z_{1}^{2}-k_{2} z_{2}^{2}-k_{3} z_{3}^{2}-k_{4} z_{4}^{2}-k_{5} z_{5}^{2}-k_{6} z_{6}^{2}
$$

From equation (36), one have $\dot{V} \leq-k_{1} z_{1}^{2}$, then

$$
V(0)-V(\infty) \geq \int_{0}^{\infty}-k_{1} z_{1}^{2} d t
$$

$V$ is bounded. According to Barbalat's lemma one can have

$$
\lim _{t \rightarrow \infty} z_{1}=0
$$

Also, one can have

$$
\lim _{t \rightarrow \infty} z_{2}=\lim _{t \rightarrow \infty} z_{3}=\lim _{t \rightarrow \infty} z_{4}=\lim _{t \rightarrow \infty} z_{5}=\lim _{t \rightarrow \infty} z_{6}=0
$$

At last, according equations (38) and (39), one can notice that motor speed, torque and rotor flux can track reference values asymptotically. 


\section{SIMULATIONS RESULTS AND DISCUSSION}

DTC-Backstepping control system block diagram is shown in Figure 1. Whenever the reference speed command $\omega^{*}$ is given, system compares it with the actual speed $\omega$. The error is used to determine the virtual reference torque $T^{*}$. The reference virtual torque is compared with actual torque $T$. The torque error obtained is used to obtain the appropriate virtual voltage vector $u_{T}$. The second reference input that is flux compare with actual flux. The error added to determinate the virtual control $X$. Like torque control loop, flux control loop is also operated to select the appropriate virtual voltage vector $u_{\psi}$. However, After the determination of the two virtual voltage vectors which used to obtain the actual voltage vectors $(\alpha-\beta)$. The two other voltage vectors $(x-y)$ are obtains from a small loop current controller. A program in Matlab/Simulink environment has been designed for both the voltage source inverter (VSI)-fed five-phase induction machine, and performed to analyze the viability of the developed control technique a number of simulations have been performed. A small prototype around $1.5 \mathrm{~kW}$ symmetrical five-phase induction machine with four poles has been used. Table 1 shows the parameters of the machine, which correspond to those of the real five-phase induction machine.

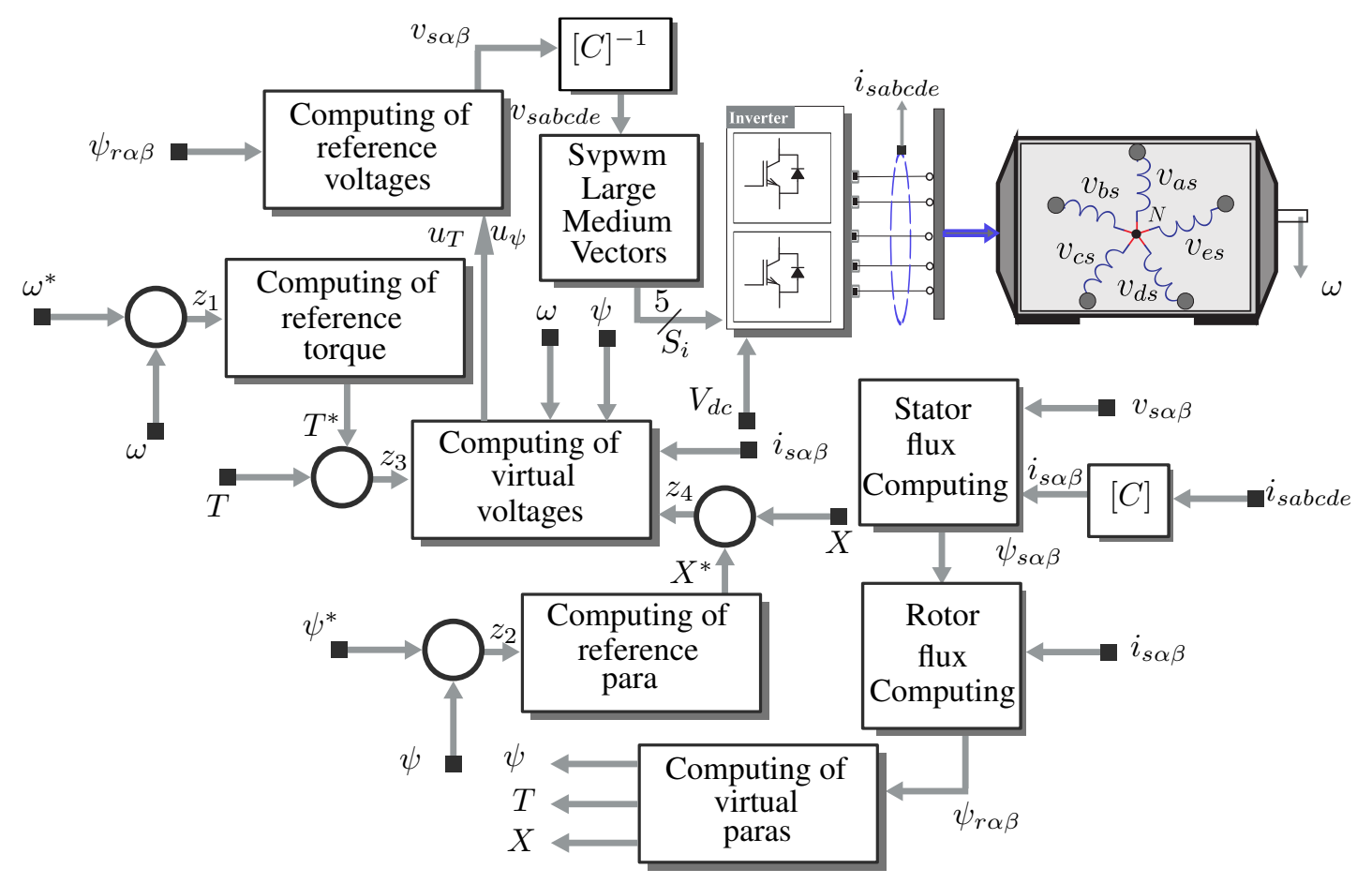

Figure 1. Scheme of Direct torque Backstepping Control of five-phase Induction Motor

Table 1. Parameters of the five-phase Induction Machine

\begin{tabular}{|c|c|c|c|}
\hline \multicolumn{4}{|c|}{ Motor Data } \\
\hline Parameters & Symbol & Value & Units \\
\hline Stator resistance & $R_{s}$ & 10 & $\Omega$ \\
\hline Rotor resistance & $R_{r}$ & 6.3 & $\Omega$ \\
\hline Mutual Inductance & $M$ & 0.42 & $\mathrm{H}$ \\
\hline Stator leakage inductance & $L_{l s}$ & 0.04 & $\mathrm{H}$ \\
\hline Rotor leakage inductance & $L_{l r}$ & 0.04 & $\mathrm{H}$ \\
\hline Moment of inertia & $J_{m}$ & 0.03 & $k g \cdot m^{2}$ \\
\hline Stator inductance & $L_{s}$ & 0.46 & $\mathrm{H}$ \\
\hline Rotor inductance & $L_{r}$ & 0.46 & $\mathrm{H}$ \\
\hline Number of pole pairs & $P$ & 2 & - \\
\hline Rated stator flux & $\psi_{n}$ & 1.27 & $\mathrm{~Wb}$ \\
\hline
\end{tabular}


Figures 2 and 3 summarize the simulation results. A start-up transient under no-load conditions, with speed references reversion from $400 \mathrm{rpm} / \mathrm{min}$ to $-400 \mathrm{rpm}$, is considered, and the motor-speed, electromagnetic-torque, stator-flux, and stator-current responses and the torque ripple are shown for both methods (DTC and DTC-Backstepping). The obtained speed response using the DTC-Backstepping method is quicker than that using the DTC method, while the settling time is practically the same. By using DTCBackstepping technique, torque ripples is reduced from 2.5 N.m to1.2 N.m as shown in figure.3. Hence torque ripple is reduced by $52 \%$. Flux ripple is reduced from $0.1 \mathrm{~Wb}$ to $0.01 \mathrm{~Wb}$ as shown in figure.3. Therefore flux ripple is reduced by $90 \%$. It is observed that the DTC-Backstepping which based on non-linear approach allows effectively to reduce torque ripple as well as flux ripple. From the simulation figures, it can be concluded that torque and flux direct backstepping control has small torque, speed, flux and current ripple. Torque and flux direct backstepping control have better performance than classical direct torque control. The scheme can not only avoid the effect of rotor resistance to rotor flux orientation, but also reduce effect of hysteresis to torque and flux. From simulation results, one view that system design can achieve direct torque and flux control and motor speed tracking performance is better than classical direct torque control. The control scheme can realize system state variable decoupling efficiently.
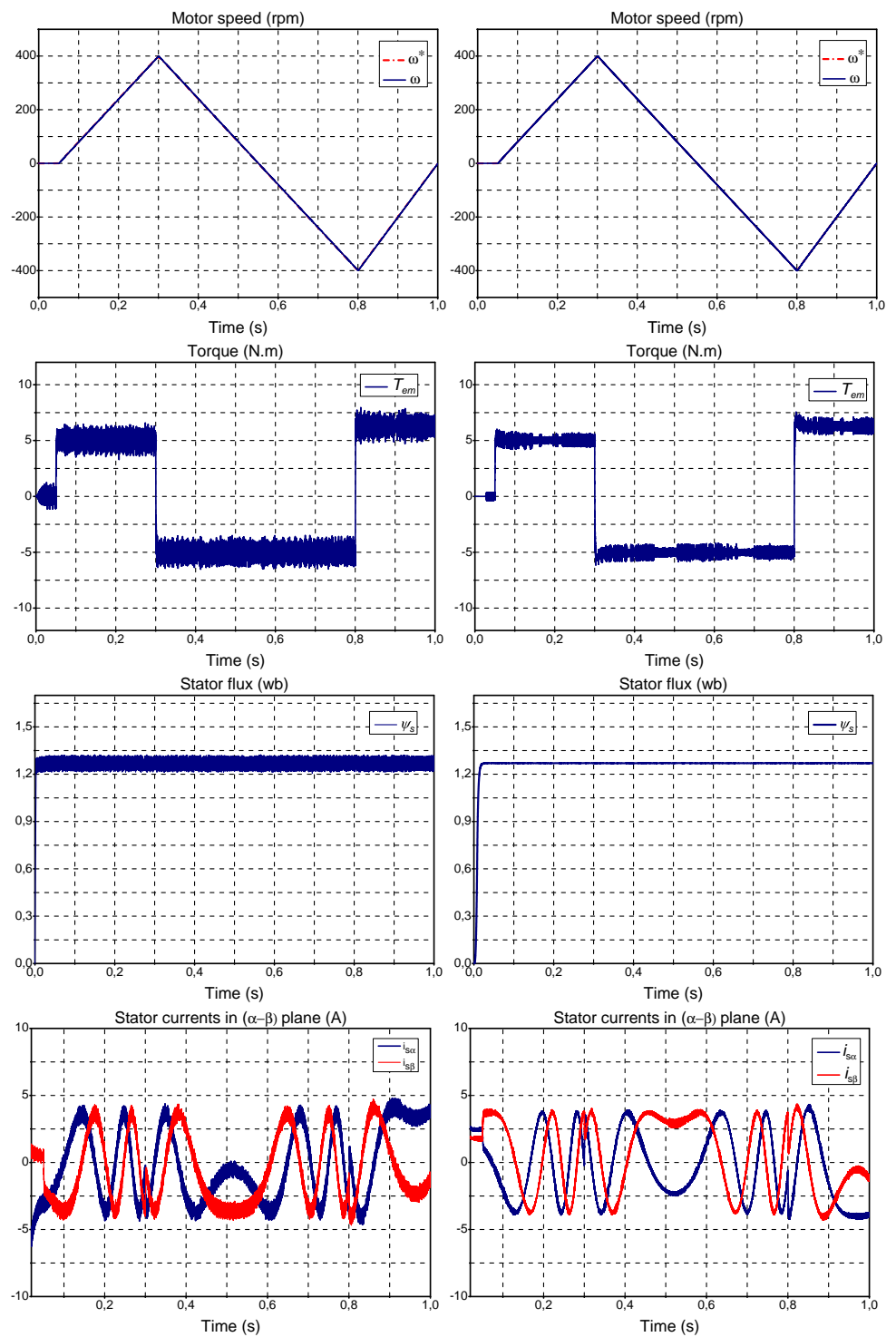

Figure 2. Motor speed,torque, stator flux and currents left side DTC and right side DTC-backstepping 

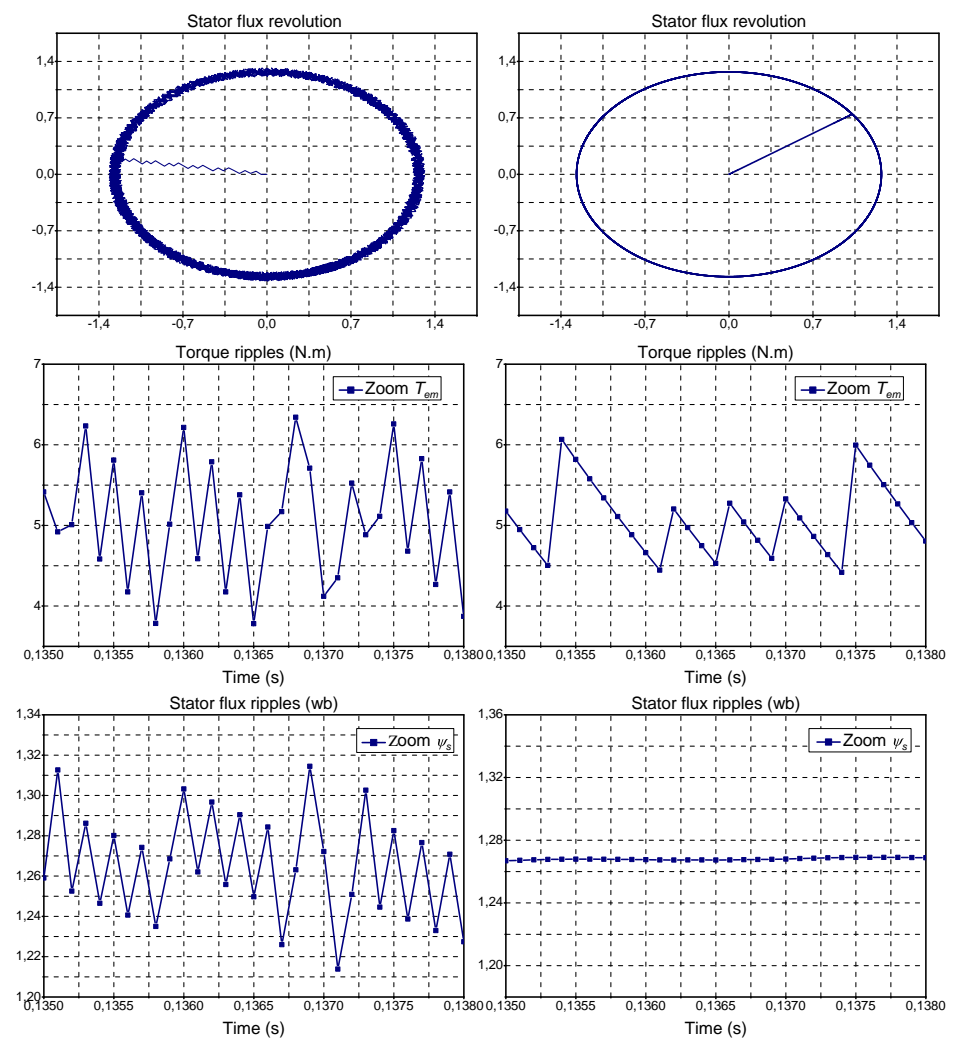

Figure 3. Stator flux revolution, torque and flux ripples, left side DTC and right side DTC-backstepping

\section{CONCLUSION}

This paper separates induction motor into mechanical part and electrical part. Backstepping coupling is applied to realize torque and flux decoupling. This can reduce the couple between state variable, and can make speed, torque and flux fast track reference values. System design is based on static coordinate of stator. The control scheme synthesize the direct torque and vector control, which not only realizes torque and rotor flux direct control, but also have the little torque and rotor flux ripple. Backstepping control design can not only provide better speed, torque and flux tracking performance, but also assert system robust performance under speed reversal. Moreover, the torque and flux are respectively reduced by $52 \%$ and $90 \%$.

\section{REFERENCES}

[1] M. Bermudez, I. Gonzalez-Prieto, F. Barrero, H. Guzman, M. J. Duran, and X. Kestelyn, ”Open-phase fault-tolerant direct torque control technique for five-phase induction motor drives," IEEE Transactions on Industrial Electronics, vol. 64, pp. 902-911, Feb 2017.

[2] H. Guzman, M. J. Duran, F. Barrero, B. Bogado, and S. Toral, "Speed control of five-phase induction motors with integrated open-phase fault operation using model-based predictive current control techniques," IEEE Transactions on Industrial Electronics, vol. 61, pp. 4474-4484, Sept 2014.

[3] H. Guzman, F. Barrero, and M. J. Duran, "Igbt-gating failure effect on a fault-tolerant predictive currentcontrolled five-phase induction motor drive," IEEE Transactions on Industrial Electronics, vol. 62, pp. 15-20, Jan 2015.

[4] H. Guzman, M. J. Duran, F. Barrero, L. Zarri, B. Bogado, I. G. Prieto, and M. R. Arahal, ”Comparative study of predictive and resonant controllers in fault-tolerant five-phase induction motor drives," IEEE Transactions on Industrial Electronics, vol. 63, pp. 606-617, Jan 2016.

[5] C. Mart 1n, M. R. Arahal, F. Barrero, and M. J. Durán, "Five-phase induction motor rotor current observer for finite control set model predictive control of stator current," IEEE Transactions on Industrial Electronics, vol. 63, pp. 4527-4538, July 2016. 
[6] M. J. Duran, J. A. Riveros, F. Barrero, H. Guzman, and J. Prieto, "Reduction of common-mode voltage in five-phase induction motor drives using predictive control techniques," IEEE Transactions on Industry Applications, vol. 48, pp. 2059-2067, Nov 2012.

[7] R. Bojoi, F. Farina, G. Griva, F. Profumo, and A. Tenconi, "Direct torque control for dual-three phase induction motor drives," in Conference Record of the 2004 IEEE Industry Applications Conference, 2004. 39th IAS Annual Meeting., vol. 2, pp. 1342-1349 vol.2, Oct 2004.

[8] X. Kestelyn, E. Semail, and D. Loroil, "Direct torque control of multi-phase permanent magnet synchronous motor drive: application to a five-phase," in IEEE International Conference on Electric Machines and Drives, 2005., pp. 137-143, May 2005.

[9] R. Shi, H. A. Toliyat, and A. El-Antably, "A dsp-based direct torque control of five-phase synchronous reluctance motor drive," in APEC 2001. Sixteenth Annual IEEE Applied Power Electronics Conference and Exposition, vol. 2, pp. 1077-1082 vol.2, 2001.

[10] H. A. Toliyat and H. Xu, "A novel direct torque control (dtc) method for five-phase induction machines," in APEC 2000. Fifteenth Annual IEEE Applied Power Electronics Conference and Exposition, vol. 1, pp. 162-168 vol.1, 2000.

[11] K. Hatua and V. T. Ranganathan, "Direct torque control schemes for split-phase induction machine," IEEE Transactions on Industry Applications, vol. 41, pp. 1243-1254, Sept 2005.

[12] R. Kianinezhad, B. Nahid, F. Betin, and G. A. Capolino, "A novel direct torque control (dtc) method for dual three phase induction motors," in 2006 IEEE International Conference on Industrial Technology, pp. 939-943, Dec 2006.

[13] B. S. Khaldi, H. Abu-Rub, A. Iqbal, R. Kennel, M. O. Mahmoudi, and D. Boukhetala, "Sensorless direct torque control of five-phase induction motor drives," in IECON 2011 - 37th Annual Conference of the IEEE Industrial Electronics Society, pp. 3501-3506, Nov 2011.

[14] Y. Tatte and M. Aware, "Direct torque control of five-phase induction motor with common-mode voltage and current harmonics reduction," IEEE Transactions on Power Electronics, vol. PP, no. 99, pp. 1-1, 2016.

[15] Z.Zhang, R.Tang, B.Bai, andD.Xie, "Novel direct torque control based on space vector modulation with adaptive stator flux observer for induction motors," IEEE Transactions on Magnetics, vol. 46, pp. 3133-3136, Aug 2010.

[16] S. Belkacem, B. Zegueb, and F.Naceri, "Robust Non-Linear Direct Torque and Flux Control of Adjustable Speed Sensorless PMSM Drive Based on SVM Using a PI Predictive Controller," Journal of Electrical Engineering and Technology Review, vol. 3, no. 1, pp. 168-175, 2010.

[17] S. Belkacem, F. Naceri, and R. Abdessemed, "Improvement in DTC-SVM of AC drives using a new robust adaptive control algorithm," International Journal of Control, Automation and Systems, vol. 9, no. 2, pp. 267-275, 2011.

[18] L. R. L. V. Raj, A. Jidin, Z. Ibrahim, K. A. Karim, M. A. Said, and M. H. Jopri, "Optimal torque control performance of DTC of 5-phase induction machine," in 2013 International Conference on Electrical Machines and Systems (ICEMS), pp. 2094-2099, Oct 2013.

[19] B. S. Khaldi, H. Abu-Rub, A. Iqbal4, R. Kennel, M. O. Mahmoudi, and D. Boukhetala, ”Comparison study between a simple sensorless method and adaptive observer for dtc-svm five-phase induction motor drive," in 2012 IEEE International Conference on Industrial Technology, pp. 743-748, March 2012.

[20] S. Lu and K. Corzine, "Direct torque control of five-phase induction motor using space vector modulation with harmonics elimination and optimal switching sequence," in Twenty-First Annual IEEE Applied Power Electronics Conference and Exposition, 2006. APEC '06., pp. 7 pp.-, March 2006.

[21] S.-Y. Kang, H.-U. Shin, and K. B. Lee, "Improved torque ripple reduction method of five-phase induction motor using fuzzy controller," in 2016 IEEE 8th International Power Electronics and Motion Control Conference (IPEMC-ECCE Asia), pp. 635-640, May 2016.

[22] M. Romero, J. Braslavsky, and M. Valla, "Ripple reduction in direct torque and flux control of induction motors via sliding modes," Latin American Applied Research, vol. 37, no. 4, pp. 289-297, 2007.

[23] C. S. Lim, E. Levi, M. Jones, N. A. Rahim, and W. P. Hew, "Fcs-mpc-based current control of a five-phase induction motor and its comparison with pi-pwm control," IEEE Transactions on Industrial Electronics, vol. 61, pp. 149-163, Jan 2014.

[24] J. A. Riveros, M. J. Durán, F. Barrero, and S. Toral, ”Direct torque control for five-phase induction motor drives with reduced common-mode voltage," in IECON 2012 - 38th Annual Conference on IEEE Industrial Electronics Society, pp. 3616-3621, Oct 2012. 
[25] C. Mart in, M. R. Arahal, F. Barrero, and M. J. Durán, "Five-phase induction motor rotor current observer for finite control set model predictive control of stator current," IEEE Transactions on Industrial Electronics, vol. 63, pp. 4527-4538, July 2016.

\section{BIOGRAPHIES OF AUTHORS}

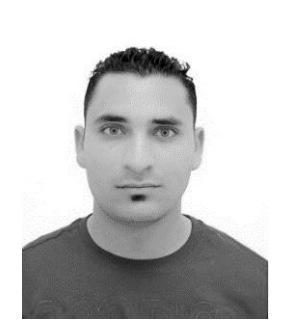

Hamdi Echeikh was born in Tozeur, Tunisia in 1988. He received his Electrical Engineer diploma and Master degree from National Engineering School of Monastir (ENIM), Tunisia in 2011 and 2013, respectively and $\mathrm{PhD}$ in Electrical Engineering in November 2018. His research interests are multiphase machine drives, renewable energies, power electronics, linear and nonlinear control systems and design of observers applied for electrical machines.

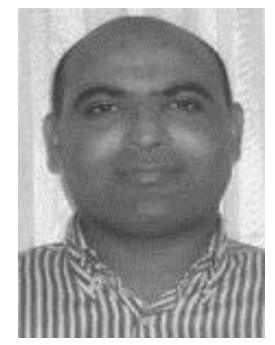

Ramzi Trabelsi was born in Sousse, Tunisia in 1976. He received his Bachelor of Science and Master from ESSTT, Tunis, Tunisia in 2001 and 2003, respectively. In 2011 he obtained his Doctorate Degree in Electrical Engineering from ENIM, Tunisia. He is currently associate professor of High Institute of Applied Sciences and Technology of Sousse (ISSATS). His research interests are electrical machines drives, multiphase machine drives, power electronics and nonlinear control systems related to electrical power engineering.

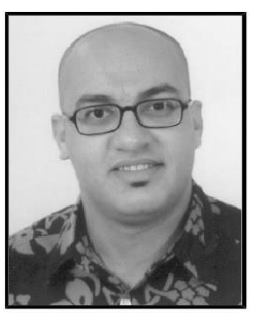

Hichem Kesraoui was born in Mahdia, Tunisia in 1979. He received his Electrical Engineer Diploma and Master Degree in 2002 and 2009 from ENIM, Monastir, Tunisia. He is currently Master Technologist Professor of Higher Institute of Technological Studies of Mahdia (ISET Mahdia). His research interests are Electrical Machines Drives, Multiphase Machine Drives, Power Electronics and Nonlinear Control Systems related to renewable energy.

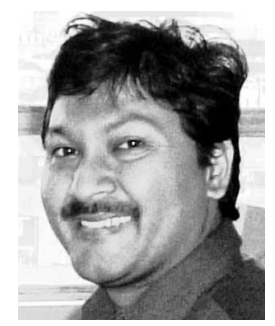

Atif Iqbal (S'04 M'09) received the B.Sc. and M.Sc.Engineering (Electrical) degrees from Aligarh Muslim University (AMU), Aligarh, India, in 1991 and 1996, respectively, and the Ph.D. degree from Liverpool John Moores University (LJMU), Liverpool, U.K., in 2006. From 1991, he was with the Department of Electrical Engineering, AMU, where he was a Lecturer and a Reader. He is currently with the Electrical and Computer Engineering Program at Texas A M University at Qatar, Doha, Qatar. His current research interests include power electronics and multiphase motor drives. Dr. Iqbal is a recipient of the Maulana Tufail Ahmad Gold Medal for standing first in B.Sc. Eng. exams in 1991, and the AMU and the Engineering and Physical Sciences Research Council (EPSRC), Govt. of U.K. Fellowship for pursuing the Ph.D. degree at LJMU.

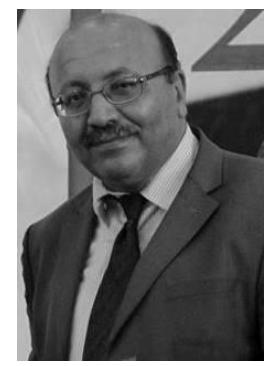

Mohamed Faouzi Mimouni received his Bachelor of Science and Master from ENSET, Tunis, Tunisia in 1984 and 1986, respectively. In 1997 he obtained his Doctorate Degree in Electrical Engineering from ENSET, Tunis. He is currently professor of electrical Engineering at National School, Monastir (ENIM), Tunisia. His specific research interests are in the area power electronics, motor drives, solar and wind power generation. 